\title{
Dumlupınar Üniversitesi Kütahya Evliya Çelebi Eğitim ve Araştırma Hastanesi Kadın Hastalıkları ve Doğum Polikliniği'ne başvuran hastaların servikal smear sonuçlarının değerlendirilmesi
}

\section{The evaluation of cervical pap-smear results of the patients who admitted to Obstetrics and Gynecology Clinic of Dumlupinar University Kutahya Evliya Celebi Training and Research Hospital}

Ali SEVEN ${ }^{1 a}$, Cengiz KOÇAK², Kadriye Beril YÜKSEL1', Suna KUCUR', İlay GÖZÜKARA', Nuh Mehmet ERBAKIRCI ${ }^{1}$, Nadi KESKIN ${ }^{1}$

${ }^{1}$ Dumlupınar Üniversitesi Tıp Fakültesi Kadın Hastalıkları ve Doğum Anabilim Dalı, Kütahya

2 Dumlupınar Üniversitesi Tıp Fakültesi Patoloji Anabilim Dalı, Kütahya, TÜRKIYE

\section{öz}

Amaç: Tüm dünyada jinekolojik kanserler önemli bir morbidite ve mortalite nedeni olarak kabul görmekte ve bu kanserler için doğru ve erken tanı/tarama yöntemlerinin önemi gün geçtikçe daha iyi anlaşılmaktadır. Bütün bunlar göz önüne alındığında biz de çalışmamızda son bir yıl içerisinde hastanemiz polikliniklerine başvuran hastaların smear sonuçlarını değerlendirmeyi amaçladık.

Gereç ve Yöntemler: Dumlupınar Üniversitesi Kütahya Evliya Çelebi Eğitim ve Araştırma Hastanesi Kadın Hastalıkları ve Doğum polikliniklerine 2013 Kasım - 2014 Ekim tarihleri arasında başvuran hastaların pap-smear sonuçlarını retrospektif olarak analiz ettik. Bu dönemde hastanemiz patoloji bölümünde konvansiyonel pap-smear yöntemi kullanılmaktaydı. Smear alınan kişiler, 21 yaşından büyük veya en az üç yıllık seksüel aktif yaşam öyküsü olan hastalardı. Polikliniklerde yapılan muayeneler sonrası konvansiyonel servikal pap-smear alınmasını kabul eden hastalara ait sonuçlar analiz edildi. Sonuçlar Bethesda 2001 sistemine göre değerlendirildi.

Bulgular: Yaklaşık olarak son bir yıllık dönem içerisinde alınan 7466 servikal smear sonucu değerlendirildi. Her sonuç grubu, transformasyon zonu (Tz) görülenler ve görülmeyenler olmak üzere iki subgruba ayrıldı. Buna göre sonuçlar; 1395 normal smear \%18,7 (406 \%5,43 Tz görüldü), 56 kandida enfeksiyonu \%0,75 (31 \%0,41 Tz görüldü), 6 trikomanas enfeksiyonu \%0,08 (2 \%0,02 Tz görüldü), 141 bakteriyel vaginosis \%1,9 (39\%0,52 Tz görüldü), 5761 diğer (atrofi, inflamasyon, postmenopazal değişiklik) \%77,16 (3298 \%44, 17 Tz görüldü). 58 ASCUS \%0,77 (36 \%0,48 Tz görüldü), 2 LSIL \%0,02, 0 HSIL, 0 AGUS, 0 ASC-H, 47 yetersiz materyal \%0,62 olarak bulundu.

Sonuçlar: Çalışmamız sonucunda, ilimizde servikal premalign lezyonların oranlarını literatüre göre daha düşük oranda bulduk. Bu durumu merkezimizde çalışan hekimlerin servikal tarama yöntemini doğru bir şekilde uygulamasına ve hasta popülasyonumuzun servikal tarama konusunda bilinçli olmasına bağladık.

Anahtar kelimeler: Konvansiyonel teknik, servikal smear, serviks kanser taraması

Sorumlu Yazara: Dr. Ali SEVEN, Dumlupınar Üniversitesi Tıp Fakültesi Kadın Hastalıkları ve Doğum Anabilim Dalı,

Kütahya, TURKEY

Phone: 00905054433176 e-mail: draliseven@hotmail.com

Received: 16.04.2015 Accepted: 01.10.2015

doi: $10.18663 /$ tjcl.64385 


\section{ABSTRACT}

Aim: All gynecologic cancers are accepted as important causes of morbidity and mortality in the world. For these cancers, importance of early diagnosis / screening methods are better understood day by day. Accordingly, in our study we aimed to evaluate the smear results of the patients who admitted to our outpatient clinic in the past year.

Material and Methods: We retrospectively analyzed pap smear results of patients who admitted to Dumlupinar University Kütahya Evliya Celebi Education and Research Hospital Obstetrics and Gynecology Outpatient Clinic between November 2013 and October 2014. In that period conventional method for pap smear was beeing used in the department of pathology of our hospital. We collected smear samples from patients who were older than 21 years old or sexually active women for at least 3 years. We analyzed the results of patients who accepted the conventional cervical pap-smear after the examinations in outpatient clinics. The results were evaluated according to the Bethesda 2001 system.

Results: The results of 7466 cervical smears which were collected in last one year were evaluated. All results were divided into 2 sub-groups as transformation zone (Tz) seen or not. According to that, 1395 (18.7\%) were normal smear (406, 5.43\% Tz), candida infection $56(0.75 \%)$ (31, 0.41\% Tz was seen), Trichomonas infection was detected on $6(0.08 \%)(2,0.02 \% \mathrm{Tz})$, $141(1.9 \%)$ showed bacterial vaginosis $(39,0.52 \% \mathrm{Tz}), 5761(77.16 \%)$ were others (atrophy, inflammation, postmenopausal changes). (3298, 44.17\% Tz), 58 (0.77\%) were ASC-US (36, 0.48\% Tz), 2 (0.02\%) LSIL, 0 HSIL, 0 AGUS, 0 ASC-H, 47 (0.62\%) were insufficient material.

Conclusion: As a result of our study we found a lower rate of cervical premalignant lesions in our city when compared to the literature. We thought that this situtaion is a result of good cervical smear screening practice of doctors working in our center and well informed patients are about cervical screening.

Key words: Conventional technique, cervical smear, cervix cancer screening

\section{Giriş}

Serviks kanseri tedavisindeki gelişmelere rağmen; erken tanı koymak, hastalığın prognozu açısından önemini halen korumaktadır. Bütün dünyada, meme kanserinden sonra kadınlarda serviks kanseri 2. sırada en sık gözlenen kanserdir $[1,2]$.Türkiye'nin deyer aldığı gelişmekte olan ülkeler grubunda, 2008 yılında kadınlarda en sık rastlanan kanser vakaları arasında serviks kanseri (453.300 yeni vaka) en sık rastlanan 2. kanser türü olarak rapor edilmiştir. Aynı yıl içerisinde, serviks kanseri, kansere bağlı ölüm sayıları arasında benzer sırada yerini korumaktadır(242.000 ile 2. kanser türü). Sağlık Bakanlığı'nın kanser kayıt verilerine göre ülkemizde serviks kanseri kadın kanserleri arasında 8. sırada yer almaktadır [3]. Günümüzde tüm dünyada jinekolojik kanserler önemli bir morbidite ve mortalite nedeni olarak kabul görmekte ve bu kanserler için doğru ve erken tanı/tarama yöntemlerinin önemi gün geçtikçe daha iyi anlaşılmaktadır.

Servikal kanserin doğal seyri tarama programına uygun olup, tarama testinin amacı prekanseröz lezyonların erkenden teşhis edilmesi ve ölümlerin önlenmesidir. Pap-smear testinin uygulamaya girmesiyle birlikte, serviks kanserine bağlı ölümler hızla (yıllık \%70'e varan) düşmeye başlamıştır [4]. Servikal sitolojinin bu denli önemli bir jinekolojik kanser tarama yöntemi olması nedeniyle; biz de kendi merkezimizin sonuçlarını literatüre sunmak istedik ve son bir yıl içerisinde hastanemiz polikliniklerine başvuran hastaların smear sonuçlarını değerlendirmeyi amaçladık.

\section{Gereç ve Yöntemler}

Gerekli izinler alındıktan sonra Dumlupınar Üniversitesi Kütahya Evliya Çelebi Eğitim ve Araştırma Hastanesi arşivinden, kadın hastalıkları ve doğum polikliniklerine 2013 Kasım 2014 Ekim tarihleri arasında başvuran hastaların pap-smear sonuçlarını retrospektif olarak analiz ettik. Bu dönemde hastanemiz patoloji bölümünde konvansiyonel pap-smear yöntemi kullanılmaktaydı. Hastanemiz polikliniklerine başvuran hastalar arasında 21 yaşından büyük veya en az 3 yıllık seksüel aktif yaşam öyküsü olan hastalara servikal papsmear tetkiki önerilmektedir. Bu öneriye olumlu yanıt veren hastalara servikal smear tetkiki uygulanmaktadır. Materyal toplanması işleminden önce hastaların obstetrik ve jinekolojik hikayeleri alınmakta ve bimanuel muayeneleri servikal örnekler alındıktan sonra yapılmaktadır. Hastalardan serviks ya da vajinadan alınmak suretiyle toplanan hücresel materyaller lam üzerine yayılarak fikse edilmekte ve kapalı kutularda patoloji bölümüne ulaştırılmaktadır. Servikal sitoloji örneği, smear fırçası eksternal servikal osa yerleştilerek ve saat yönünde $360^{\circ}$ çevrilerek alınmaktadır. Yukarıda belirtilen tarihler arasında materyal alınması için Cerviks Brush smear fırçası (Gaziemir - İzmir / Turkey) kullanıldı. Smear sonuçları Bethesda 2001 sistemine göre değerlendirildi ve transformazsyon zonu görülüp / görülmemesine göre kendi içerisinde iki gruba ayrıldı.

Genel olarak polikliniklere başvuran hastalar arasında, materyal toplanmasına engel olduğu düşünülen kanama, ilişki, vajinal ilaç kullanımı ya da duş hikayeleri sözel olarak sorgulanır ve uygun olmayan öykü verenlerden smear alınmaz. 


\section{Bulgular}

Kayıtlar tarandıktan ve retrospektif analiz yapıldıktan sonra ortaya çıkan sonuçlar tüm hastalar ve Tz görülen hastalar şeklinde grafik üzerinde gösterilmiştir (Şekil 1). Sonuç olarak; 1395 normal smear \%18,7 (406 \%5,43 Tz görüldü), 56 kandida enfeksiyonu \%0,75 (31 \%0,41 Tz görüldü), 6 trikomanas enfeksiyonu \%0,08 (2 \%0,02 Tz görüldü), 141 Bakteriyel vaginosis \%1,9 (39 \%0,52 Tz görüldü), 5761 Diğer (atrofi, inflamasyon, postmenopazal değişiklik) \%77,16 (3298 \%44,17 Tz görüldü). 58 ASCUS \%0,77 (36 \%0,48 Tz görüldü), 2 LSIL $\%$ 0,02, 0 HSIL, 0 AGUS, 0 ASC-H, 47 yetersiz materyal $\% 0,62$ olarak bulundu.

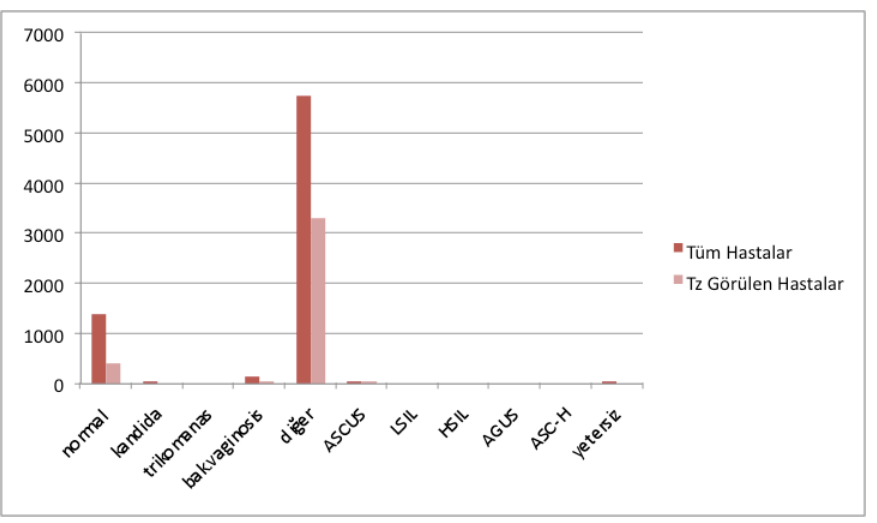

Şekil 1. Tüm Hastalar ve Tz Görülen Hastaları gösteren grafik

\section{Tartışma}

Serviks kanseri sık görülen jinekolojik kanserler arasında yerini korumaktadır. Bu malignitenin önlenmesi veya tedavi edilebilmesi; risk faktörlerinin belirlenmesi, önlenebilir olanların ortadan kaldırılması, uygun yaş grubunda uygun tarama testlerinin yapılmasıyla erken tanı ve tedavinin yapılmasına bağlıdır [5]. Taramanın etkin bir şekilde uygulandığı gelişmiş ülkelerde Pap-smear testi mükemmel sonuçlar vermiştir. Ülkemizde de 2008 yılından itibaren Kanser Erken Teşhis Tarama ve Eğitim Merkezi (KETEM) serviks kanser taraması için 35 - 65 yaş aralığındaki kadınlara, 5 yılda bir kez Pap-smear testi yaparak tarama programını yürütmektedir. Bu uygulamanın, ülkemizde servikskanserinin insidans ve prevalansındaazalma sağlayacağını düşünmekteyiz ancak taramanın 35 yaşında başlaması yeterli değildir. Türkiye 'de 35 yaş üstü uygulaması sağlık bakanlığı'nın önerisi üzerine KETEM'lerde yapılmaktadır. KETEM belli yaş grubuna yönelik uygulamalarda bulunmaktadır. Hekimler bütün topluma yönelik çalıştığı için uluslararası alanda konusunda otör cemiyetlerin kılavuzlarına riayet etmek durumundadır. Bu konuda otör cemiyetlerden birisi de Amerikan Kolposkopi ve Servikal Patoloji Cemiyeti (AKSPC)'dir. Bu cemiyetin önerisine uygun olarak; tarama yaşı ve aralığının literatürde belirtilen 21 yaş veya ilk cinsel aktiviteden itibaren 3 yıl sonraya çekilmesinin sonuçları daha iyi hale getireceğini düşünmekteyiz [6].

Çalışmamızın sonuçlarını, daha önce yapılan çalışmalarla bir tablo üzerinde karşılaştırdık (Tablo 1). Daha önce yapılan çalışmalarda pap-smear yetersiz materyal oranı \%0,5 - 7,2 arasında değişmekle birlikte oratalama değeri \%0,5 şeklinde bildirilmiştir [7-12]. Daha önce yapılan bir çalışmada dünyada ortalama yetersizlik oranı \%0,5 olarak bildirilmiştir [13]. Çalışmamızda bulduğumuz \%0,62 yetersiz materyal oranı bu değerin üzerinde olmakla beraber kabul edilebilir sınırlarda olduğu gözlenmiştir. Literatürdeki çalışmalarda farklı oranlar olmakla birlikte bir patoloji laboratuvarında incelenen Papsmearlar pap-smear testleri, ASC-US oranının ortalama $\% 4,4$ olmalıdır. Bir diğer kalite kontrol indikatörü olarak ASCUS/LSIL oranı gösterilmektedir [12,13]. Bethesda Sistemi 2001 'de bu oran 1/1 olarak öngörülmüştür [14]. ABD'de yapılan oldukça kapsamlı bir çalışmaᄀda Rosemarie ve ark [15] her yıl incelenen 55 milyon pap-smearın \%1 - \%10,4'ünde ASC-US tanımlanmıştır. Fındık ve ark'nın [16] yaptığı çalışmada, dâhil edilen olgulardan 10938 olguda smear sonuçları normal, 136 $(\% 1,2)$ olguda anormal bulunmuştur. ASC-US'un insidansı $\% 0,7$ olarak, LGSIL'in insidansı \%0,4, diğerlerinin insidansı $\% 0,1$ olarak bulunmuştur. Anormal smear sonuçlarında 74'ü (\%55) ASC-US, 2'si (\%2) ASC-H, 44'ü (\%32) LGSIL, 6'sı (\%4) HGSIL, 3'ü (\%2) invaziv kanser ve 7'si (\%5) AGC olarak tespit edilmiştir. ASC-US oranı 0,7 ASC-US/LGSIL oranı ise 1,71 olarak bulunmuştur. Türk Servikal Kanser ve Servikal Sitoloji Araştırma Grubu'nun 33 merkezle birlikte yürüttüğü 140334 hastanın bulunduğu çalışmada, ülkemizde ASC-US prevalansı $\% 1,07$, LGSIL \%0,3, HGSIL \%0,17 olarak bulunmuştur [17].

Tablo 1. Pap smear test sonuçlarının farklı çalışmalarla karşılaştırılması [7-12,17].

\begin{tabular}{|l|l|l|l|l|l|l|l|}
\hline & AGUS/AGC \% & ASCUS \% & LGSIL \% & HGSIL \% & SCC \% & Ülke & Olgular (n) \\
\hline Insınga ve ark. [7] & 0,2 & 3,3 & 1,2 & 0,3 & 0,017 & A.B.D & 150.052 \\
\hline Ayhan ve ark. [17] & 0,08 & 1,07 & 0,3 & 0,17 & 0,04 & Türkiye & 140.334 \\
\hline Yaltı ve ark. [8] & 0,1 & 2,45 & 0,23 & 0,15 & 0,003 & Türkiye & 28.469 \\
\hline Gupta ve ark. [9] & 0,3 & 3,36 & 0,99 & 0,34 & 0,41 & Hindistan & 29.475 \\
\hline Fonn ve ark. [10] & - & - & 2,42 & 1,8 & 0,47 & Güney Afrika & 20.603 \\
\hline Ghazal-aswad ve ark. [11] & 0,07 & 1,71 & 0,77 & 0,54 & 0 & Birleşik Arap Emirlikleri & 4.053 \\
\hline Bacanakgil ve ark. [12] & 0.2 & 4.2 & 0.6 & 0.15 & 0.1 & Türkiye & 4.122 \\
\hline Çalışmamız & 0 & 0.77 & 0.02 & 0 & 0 & Türkiye & 7.466 \\
\hline
\end{tabular}


Şanlıurfa'da gerçekleştirilen toplum bazlı tarama programında ise yaklaşık 10.000 smear alınmış olup, 144 tanesinde $(\% 1,6)$ ASC-US, 6 tanesinde $(\% 0,06)$ ASC-H, 7 tanesinde $(\% 0,07)$ LGSIL, 2 tanesinde $(\% 0,02) \mathrm{HGSIL}, 1$ tanesinde $(\% 0,01)$ ise skuamöz hücreli karsinom tespit edilmiştir [18]. Bayramov ve ark [19] anormal smear sonuçlarını \%63,9 ASCUS, \%3,4 AGC, \%23 LGSIL ve \%10,4 HGSIL olarak bulmuştur. Abalı ve ark'nın [20] yaptığı çalışmada anormal smear sonuçları 256 olguda ASCUS (\%68,4), 21 olguda ASC-H (\%5,6), 31 olguda LSIL $(\% 8,2), 48$ olguda HSIL (\%12,8), 18 olguda invaziv karsinom $(\% 4,8)$ olarak gelmiştir. Inoue ve ark.'nın [21] çalışmasında, LSIL \%6, HSIL \%1,1, karsinoma \%0,2 olarak bulunmuştur. Dugan ve ark'nın [22] çalışmasında, ASCUS \%3, LSIL \%10, HSIL \%2 olarak bulunmuştur. Bizim çalışmamızda ise yetersiz smear oranı 0,6, ASCUS oranı 0,7, LGSIL oranı 0,4 olarak bulunmuştur.

Serviks kanserinin en sık görülen jinekolojik kanserlerden birisi olması ve servikal premalign lezyonların erken tanısı ile yapılacak müdahaleler sayesinde önlenebilmesi açısından, pap-smear testi kadın hastalıkları ve doğum hekimleri açısından önemli bir patoloji tarama tetkikidir. Pap-smear testinin önemini vurgulamak açısından, literatüre katkısı olacağını düşündüğümüz bu çalışmanın kısıtlayıcı unsurları ise retrospektif bir analiz olması ve smear sonuçlarının incelendiği tarihte konvansiyonel yöntemin kullanılmış olmasıdır. Bu testin polikliniğe başvuran hastalara literatürde belirtilen aralıklarla önerilmesi gerekmektedir. Hatta toplumun geneline pap-smear ve diğer kanserlerin taramaları açısından eğitim programları uygulanmasının yararlı olacağını düşünmekteyiz. Servikal taramanın hangi aralıklarla yapılacağı konusu ise Amerikan Kolposkopi ve Servikal Patoloji Cemiyeti'nin 2012 yılında güncellenen son kılavuzunda açıkça belirtilmiştir [6]. Bu kılavuzda 21 yaşından önce servikal tarama önerilmemekte ve yine bu yaş grubunda tespit edilen AS-CUS olgularının yönetiminde HPV testi yapılması önerilmemektedir. 21-29 yaş arasında 3 yılda bir yapılmak üzere servikal smear testi, 30-65 yaş arasında 5 yılda bir yapılmak üzere HPV ve servikal smear testinin birlikte yapılması ya da HPV testi yapılamayan merkezler için 3 yılda bir uygulanmak üzere sadece servikal smear testi yapılmasının uygun olduğu belirtilmiştir. 65 yaş üzerinde ve histerektomi sonrasında, önceden yapılmış yeterli ve tekrarlayan negatif servikal sitoloji sonucu olanlarda tarama yapılmasına gerek yoktur [6].

Sonuç olarak, ilimizde servikal premalign lezyonların oranlarını literatüre göre daha düşük oranda bulduk. Bu durumu merkezimizde çalışan hekimlerin servikal tarama yöntemini doğru bir şekilde uygulamasına ve hasta popülasyonumuzun servikal tarama konusunda bilinçli olmasına bağladık. Bu sonuçlardan yola çıkarak Kütahya ilinde daha geniş hasta serisi içeren, Human Papilloma Virüs (HPV) insidansının ve tiplerinin ortaya konulacağı, randomize prospektif bir çalışmanın yapılmasının literatüre katkısı olacağı kanaatine vardık.

\section{Çıkar çatışması ve Finansman Beyanı}

Bu çalışmada çıkar çatışması ve finansman destek alındığı beyan edilmemiştir.

\section{Kaynaklar}

1. Berek JS. Novak's Gynecology. In: Adams Hillard P, Adashi E, editors. Meme Kanseri. Philadelphia,PA: Lippincott Williams \& Wilkins Publishing, 2002: 1375-1398.

2. Burden of cervical cancer globally. WHO/ICO Information Center on HPV and Cervical Cancer. 2011. http://www.who.int/ hpvcentre/en/ (Accessed July17, 2011).

3. Eser SY, Karakoc H. Cancer Incidence in Turkey. Ed. Tuncer M. In: Cancer Control in Turkey, Sağlık Bakanlığı Basım Numarası:776, 2010, Ankara p:35-50.

4. Nanda K, McCrory DC, Myers ER, et al. Accuracy of the Papanicolaou test in screening for and follow-up of cervical cytologic abnormalities: a systematic review. Ann Intern Med 2000; 132: 810-9.

5. Sasieni, P, Adams J, Cuzick J. Benefit of cervical screening at different ages: evidence from the UK audit of screening histories. Br J Cancer 2003: 89: 88-93.

6. Saslow D, Solomon D, Lawson HW, et al. American Cancer Society, American Society for Colposcopy and Cervical Pathology, and American Society for Clinical Pathology screening guidelines for the prevention and early detection of cervical cancer. J Low Genit Tract Dis 2012; 16: 175-204.

7. Insinga RP, Glass AG, Rush BB. Diagnoses and outcomes in cervical cancer screening: A populationbased study. Am J Obstet Gynecol 2004; 191: 105-13.

8. Yalti S, Gürbüz B, Bilgiç R, Cakar Y, Eren S. Evaination of cytologic screening results of cervix. Int J Gynecol Cancer 2005; 15: 292-4.

9. Gupta S, Sodhani P, Hadler K, et al. Spectrum of epithelial cell abnormalities of uterine cervix in a cervical cancer screening programme: Implications for resource limited settings. Eur J Obstet Gynecol Reprod Biol 2007; 134: 238-42.

10. Fonn $S$, Bloch B, Mabina $M$, et al. Prevalence of pre-cancerous lesions and cervical cancer in South Africa-a multicentre study. $S$ Afr Med J 2002; 92: 148-56.

11. Ghazai-Aswad S, Gargash H, Badrioatlı P, et al. Cervical smear abnormalities in the United Arab Emirates: a pilot study in the Arabian Gulf. Acta Cytol 2006; 50: 41-7.

12. Bacanakgil H, Bozkurt T, Çelik S, Dursun N, Pirusa S, Boran B. Servikal smear tarama profil ve sonuçları (4122 olgu). Istanbul Tip Dergisi 2008: 4; 1758-81.

13. Jones BA, Davey DD. Qualty management in gynecologic cytology using interlaboratory comparison. Arch Patbol Lab Med 2000; 124: 672-81.

14. Solomon D, Nayar R, Davey $D$, et al. The Bethesda system for reporting cervical cytology, Second edition, 2004; 1-7: 1157.

15. Rosemarie R, Fadare O. Longitudinal cytological folow-up of patients with a Papanicolaou Test interpretation of atypical squamous cells of undetermined significance that was followed by a negative reflex test for high-risk Human Papillomavirus Types. Int J Gynecol Path 2007; 27: 108-112.

16. Fındık M.F, Mihmanlı V, Mirza T, Ulupınar N,Taşdemir D. Kadın Hastalıkları ve Doğum Polikliniğimize başvuran hastalara yapılan pap-smear sonuçlarının değerlendirilmesi. Okmeydanı Tıp Dergisi 2012; 28: 142-5. 